\title{
Aviation Fuel Gauging Sensor Utilizing Multiple Diaphragm Sensors Incorporating Polymer Optical Fiber Bragg Gratings
}

Marques, C. A. F.; Pospori, A.; Saez-Rodriguez, D.; Nielsen, Kristian; Bang, Ole; Webb, D. J.

Published in:

I E E E Sensors Journal

Link to article, DOI:

10.1109/JSEN.2016.2577782

Publication date:

2016

Document Version

Peer reviewed version

Link back to DTU Orbit

Citation (APA):

Marques, C. A. F., Pospori, A., Saez-Rodriguez, D., Nielsen, K., Bang, O., \& Webb, D. J. (2016). Aviation Fuel Gauging Sensor Utilizing Multiple Diaphragm Sensors Incorporating Polymer Optical Fiber Bragg Gratings. I E E E Sensors Journal, 16(15), 6122-6129. https://doi.org/10.1109/JSEN.2016.2577782

\section{General rights}

Copyright and moral rights for the publications made accessible in the public portal are retained by the authors and/or other copyright owners and it is a condition of accessing publications that users recognise and abide by the legal requirements associated with these rights.

- Users may download and print one copy of any publication from the public portal for the purpose of private study or research.

- You may not further distribute the material or use it for any profit-making activity or commercial gain

- You may freely distribute the URL identifying the publication in the public portal 


\title{
Aviation fuel gauging sensor utilizing multiple diaphragm sensors incorporating polymer optical fiber Bragg gratings
}

\author{
C. A. F. Marques, A. Pospori, D. Sáez-Rodríguez, K. Nielsen, O. Bang, D. J. Webb, Member, IEEE
}

\begin{abstract}
A high performance fuel gauging sensor is described that uses five diaphragm-based pressure sensors, which are monitored using a linear array of polymer optical fiber Bragg gratings. The sensors were initially characterized using water, revealing a sensitivity of $98 \mathrm{pm} / \mathrm{cm}$ for four of the sensors and $86 \mathrm{pm} / \mathrm{cm}$ for the fifth. The discrepancy in the sensitivity of the fifth sensor has been explained as being a result of the annealing of the other four sensors. Initial testing in JET A-1 aviation fuel revealed the unsuitability of silicone rubber diaphragms for prolonged usage in fuel. A second set of sensors manufactured with a polyurethane based diaphragm showed no measurable deterioration over a 3 month period immersed in fuel. These sensors exhibited a sensitivity of $39 \mathrm{pm} / \mathrm{cm}$, which is less than the silicone rubber devices due to the stiffer nature of the polyurethane material used.
\end{abstract}

Index Terms - Fiber Bragg gratings, Polymer optical fiber sensors, Pressure sensors, Fuel level monitoring, Aircraft applications.

\section{INTRODUCTION}

$\mathrm{F}$ UEL level monitoring has always been a technical challenge. Generally, in aircraft fuel systems [1] the most frequently used level sensors are the capacitive and ultrasonic

Manuscript received April 21, 2016; revised April XX, 2016; accepted April XX, 2016. Date of publication XX XX, 2016; date of current version XX XX, 2016. This work was supported by Marie Curie Intra European Fellowships included in the 7th Framework Program of the European Union (projects PIEF-GA-2013-628604 and PIEF-GA-2011-302919). C. A. F. Marques is grateful for the FCT Fellowship (SFRH/BPD/109458/2015). The research leading to these results has also received funding from the People Programme (Marie Curie Actions) of the European Union's Seventh Framework Programme FP7/2007-2013/ under REA grant agreement No. 608382.

C. A. F. Marques is with the Aston Institute of Photonic Technologies, Aston University, B4 7ET, Birmingham, U.K., Instituto de Telecomunicações and Physics Department \& I3N, Universidade de Aveiro, 3810-193 Aveiro, Portugal (e-mail: c.marques@aston.ac.uk, cmarques@av.it.pt).

A. Pospori is with the Aston Institute of Photonic Technologies, Aston University, B4 7ET, Birmingham, U.K. (e-mail: a.posporis@aston.ac.uk).

D. Sáez-Rodríguez is with the Comunicaciones Opticas, Universidad Politecnica de Valencia, Valencia 46022, Spain (e-mail: dasaerod@upv.es).

K. Nielsen, O. Bang are with the DTU Fotonik, Department of Photonics Engineering, Technical University of Denmark, DK-2800 Kgs. Lyngby, Denmark (e-mail: krini@fotonik.dtu.dk, oban@fotonik.dtu.dk).

D. J. Webb is with the Aston Institute of Photonic Technologies, Aston University, B4 7ET, Birmingham, U.K. (e-mail: d.j.webb@ aston.ac.uk).

Color versions of one or more of the figures in this paper are available online at http://ieeexplore.ieee.org.Digital Object Identifier 10.1109/IEEE.2016.XXX devices, however they suffer from intrinsic safety concerns in explosive environments combined with issues relating to reliability and maintainability. In recent years, many optical fiber liquid level sensors have been reported to be safe and reliable and present many advantages for aircraft fuel measurement [2]. Above all, water mixed in the fuel will have little influence on optical fiber based liquid level sensors. Different optical fiber liquid level sensors have been developed, such as the pressure type, float type, optical radar type, total internal reflection type and side-leaking type [1,35]. Amongst these, many types of liquid level sensors based on fiber gratings have been demonstrated [6-11], including fiber Bragg gratings (FBGs), long period gratings, and tilted FBGs. However, these sensors have not been commercialized because they exhibit some drawbacks, such as low sensitivity, limited pressure range, long-term instability, limited resolution, high cost, weakness, and are complicated to manufacture. In addition, any sensors that involve direct interaction of the optical field with the fuel (either by launching light into the fuel tank or via the evanescent field of a fiber-guided mode) must be able to cope with the potential build up of contamination - often bacterial - on the optical surface.

We recently proposed an alternative optical approach utilizing multiple diaphragm-based pressure sensors, where the diaphragm deflection was monitored by embedded polymer optical fiber Bragg grating strain sensors [12]. The sensors are placed at different heights in the liquid tank (see Fig. 1) and the level determined by linear regression using the readings from the submerged sensors. This approach has several advantages:

i. Fault tolerance: malfunctioning sensors can be identified and their outputs ignored;

ii. Operation independent of fuel density: changing the density alters the slope of the fitted line, but not its intercept;

iii. Operation insensitive to g-force: this again changes the slope of the line but not its intercept;

iv. Temperature insensitivity: temperature induced shifts in both the nominal Bragg wavelengths of the sensors and the sensitivity of the sensors are compensated for.

It should be noted that the aircraft fuel gauging problem is particularly demanding since not only can the effective g-force vary due to acceleration, but the attitude of the plane to the 


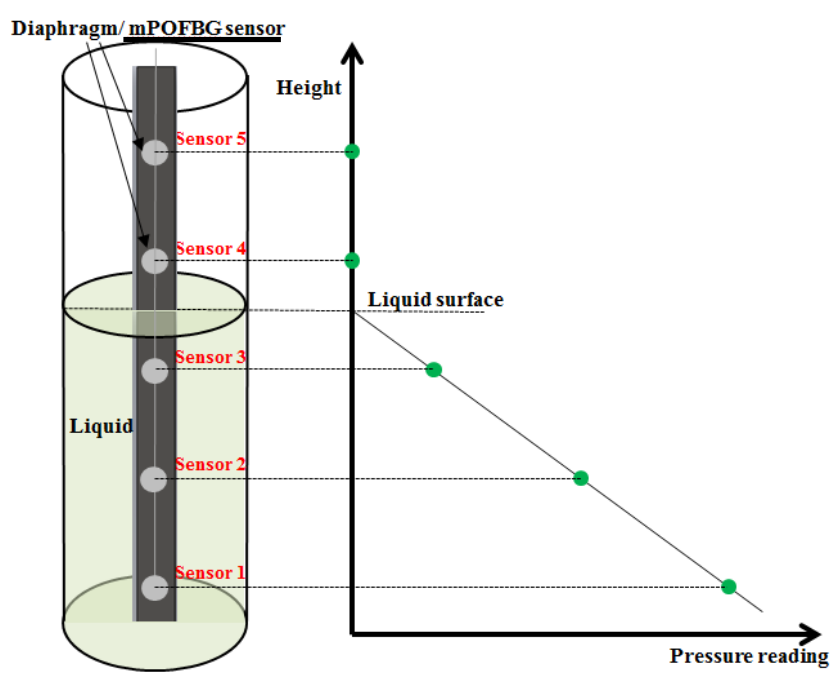

Fig. 1. Liquid level sensing approach using multiple pressure sensors. Left: sensor locations. Right: Level determination by linear regression to readings from submerged sensors.

effective gravitational force an also change: in other words the plane of the liquid surface can have different orientations with respect to the airframe structure. This is a problem common to almost all gauging systems and is solved by having multiple level gauges coupled with appropriate signal processing.

In this paper we build on the basic, proof-of-principle work reported in [12] where water was used as the liquid to be gauged and [13] where the response of the sensor was modeled. We report on experiments that reveal important engineering problems with the approach, for which we provide some solutions. Firstly we discover and characterize the role that annealing has on the sensor stress sensitivity. Secondly, we perform the first tests of our system using Jet A-1 aviation fuel; to enable long-term use in this environment we move to a polyurethane diaphragm, resistant to the fuel.

\section{Proposed SEnSor: FAbrication AND SENSING PRINCIPLE}

Five Bragg gratings were inscribed in a microstructured polymer optical fiber (mPOF) fabricated from poly(methyl methacrylate) (PMMA) and doped with benzyl dimethyl ketal (BDK) photoinitiator - for details of the fabrication see [14]. The $\mathrm{mPOF}$ has a core diameter of $6 \mu \mathrm{m}$ and an outer diameter of $125 \mu \mathrm{m}$ and a loss of about $7 \mathrm{~dB} / \mathrm{m}$ at $850 \mathrm{~nm}$. Using a single $75 \mathrm{~cm}$ long fiber, the five multiplexed mPOFBGs are inscribed spatially separated by $15 \mathrm{~cm}$ using a CW $\mathrm{He}-\mathrm{Cd}$ laser with an output power of $30 \mathrm{~mW}$ at $325 \mathrm{~nm}$. The inscription process was monitored using a continuous wave, super-luminescent diode from Superlum centered at $835 \mathrm{~nm}$ (with a power output of $1.25 \mathrm{~mW}$ over a spectrum width of 50 $\mathrm{nm}$ ) with FC/APC terminated pigtail and an optical spectrum analyzer (OSA) connected to an $850 \mathrm{~nm}$ single-mode silica fiber coupler. To obtain five gratings with different wavelengths, two different phase masks were used with pitches of 557.5 and $580 \mathrm{~nm}$ and thermal annealing of the inscribed fiber was used to change the Bragg wavelengths [15]. The reflection and transmission spectra of the sensors are shown in Figs. 2 (a) and (b), respectively. The nominal sensor wavelengths are $823.98 \mathrm{~nm}$ (sensor 1), $830.04 \mathrm{~nm}$ (sensor2), $833.90 \mathrm{~nm}$ (sensor3), $837.21 \mathrm{~nm}$ (sensor 4) and $839.26 \mathrm{~nm}$ (sensor 5). Following grating inscription, the $\mathrm{mPOF}$ containing the FBGs was UV-glued (Loctite 3936) to one $8^{\circ}$ angled silica fiber pigtail. This multiplexed array of POFBGs is the largest reported to-date, indicative of the maturing nature of the technology.

For the diaphragm manufacture, a silicone rubber solution was prepared by mixing homogeneously two liquids [16]

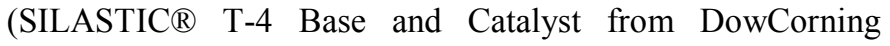
Corporation) in a ratio of $100: 10$ by volume. The prepared silicone rubber solution was poured in a $50 \mathrm{~mm}$ diameter plastic container with a height of $1.1 \mathrm{~mm}$ (see Fig. 2 (c)), in which was also placed the POF containing one of the FBGs. The diaphragm fabrication is a key step in the sensor fabrication and considerable care was taken to ensure the mPOFBG was at the center of each diaphragm (see Figs. 2 (c) and (d)) to obtain the same sensitivity in each sensor. With regard to uniformity, the diaphragms obtained had thicknesses around $1.08 \pm 0.01 \mathrm{~mm}$, as measured using digital calipers. Calculations were made to obtain the same volume of silicone rubber solution in each diaphragm. The mold was kept undisturbed for 24 hours at room temperature to allow the silicone rubber to set. More details of the fabrication method can be found in [12].
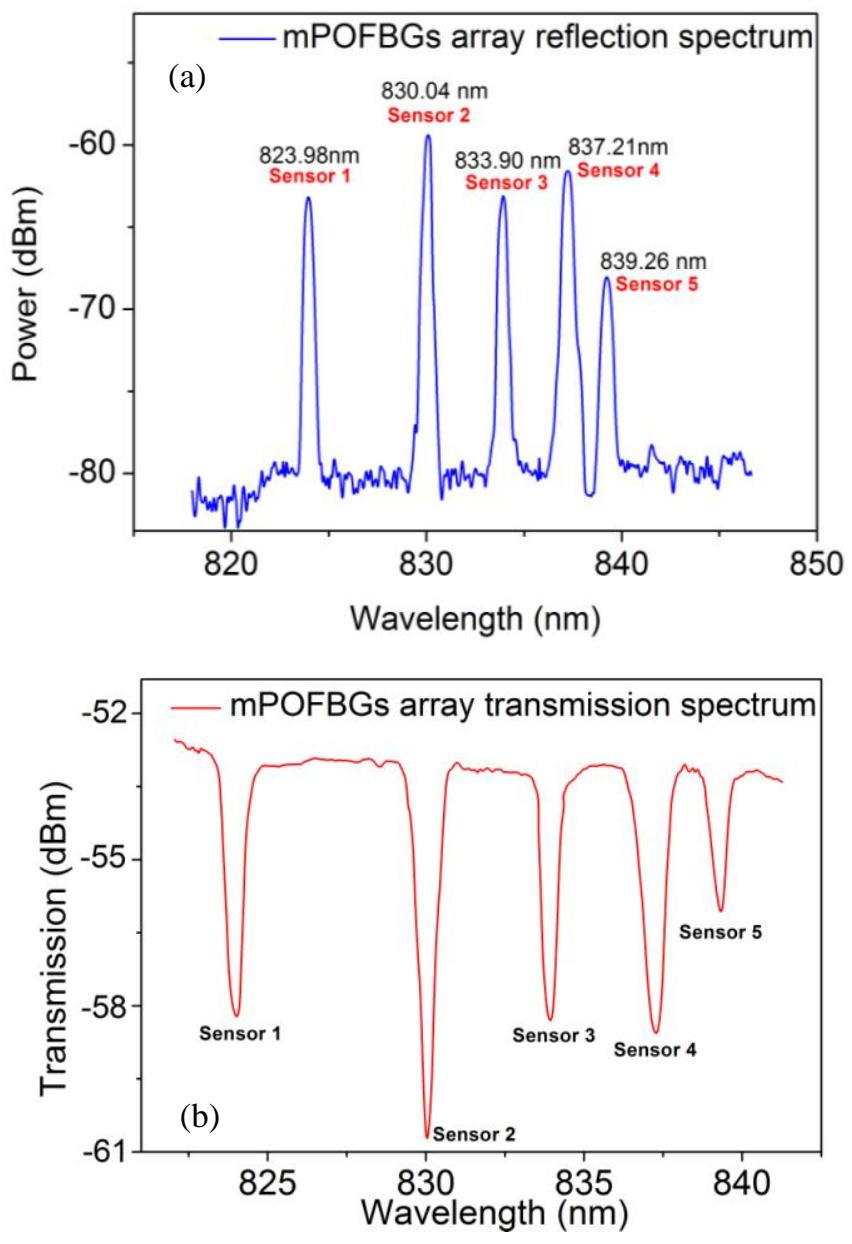

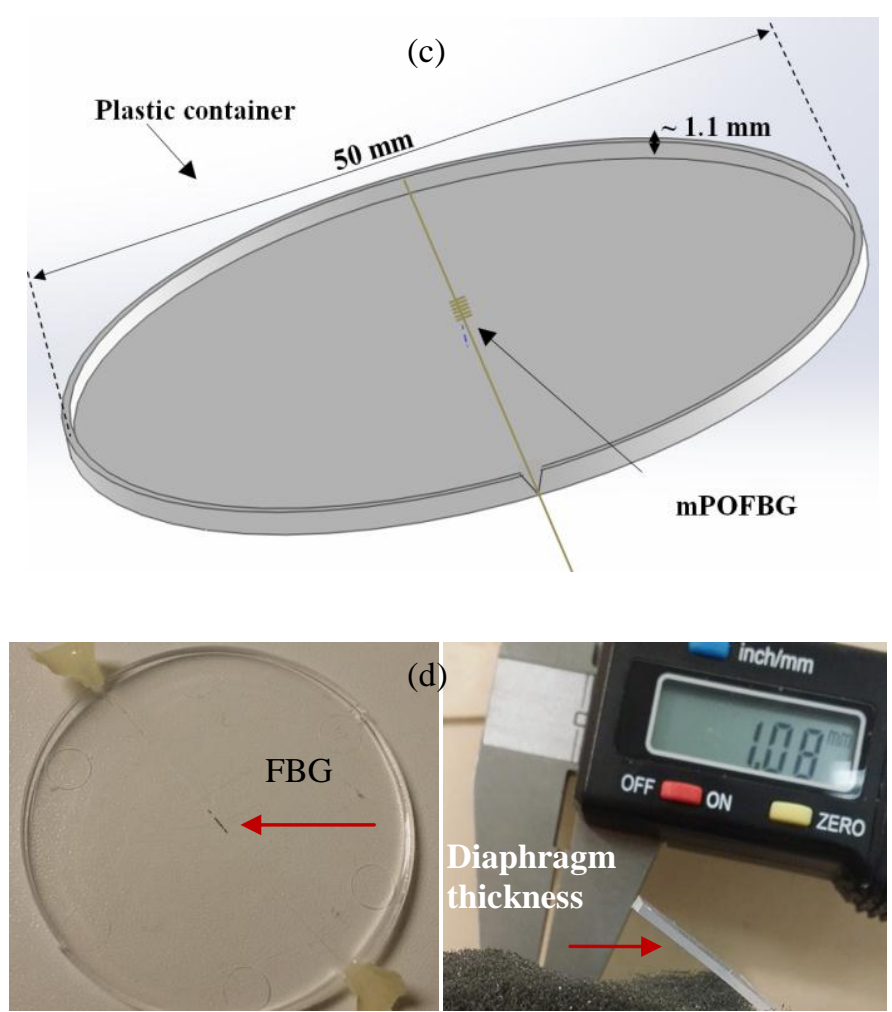

Fig. 2. (a) Reflection and (b) transmission spectra of mPOFBG array with five multiplexed gratings. (c) Plastic container used for the diaphragm fabrication and (d) an image of the silicone rubber diaphragm.

The design of the prototype multiple sensor system consists of a square acrylic tube $(800 \mathrm{~mm}$ length, with $3.2 \mathrm{~mm}$ wall thickness and $38.1 \mathrm{~mm}$ outside dimension), with windows drilled at equidistant positions along it as shown in Fig. 3. It contains five sensors positioned over $15 \mathrm{~mm}$ diameter holes spatially separated by $150 \mathrm{~mm}$. A judgment was made that 5 sensors were sufficient to demonstrate the proof of principle of our level sensing approach and allow evaluation. In an engineering application the number of sensors would be a design parameter to be optimized, since more sensors would improve system performance but increase complexity and therefore cost. The sensors were then placed and sealed at positions aligned with the window positions such that the FBG center was aligned with the window center. A thin layer of silicone sealant was used to seal effectively the sensing area and a slight strain was applied to the diaphragm when it was sealed to avoid hysteresis effects. Furthermore, a retaining ring was used in each sensor, with the diaphragm sandwiched between the tube and retaining ring. Eight screws were used to hold the tube and retaining ring together, producing a strong seal (see Fig. 3 (a). With the tube sealed at the bottom, and open at the top, the atmospheric pressure inside the tube remains essentially constant. The system relies on increasing hydrostatic pressure from liquid outside the sensing tube deforming the diaphragms causing the fiber to become elongated, which results in a positive shift in the Bragg wavelength; otherwise, the internal pressure matches the external pressure and the diaphragm is not deformed.

\section{EXPERIMENTAL PROCEDURE/DETAILS}

The experimental setup for evaluation of the liquid level sensitivity of the sensor is depicted in Fig. 3. The sensor responses were monitored and the data were collected with the super-luminescent diode and OSA used to monitor the inscription process. When the liquid level in the container rises, we deform the submerged diaphragms and consequently induce a positive shift in the Bragg wavelength is achieved. Some initial tests of the response time of the sensors were carried out before collecting the data to determine liquid level sensitivity,
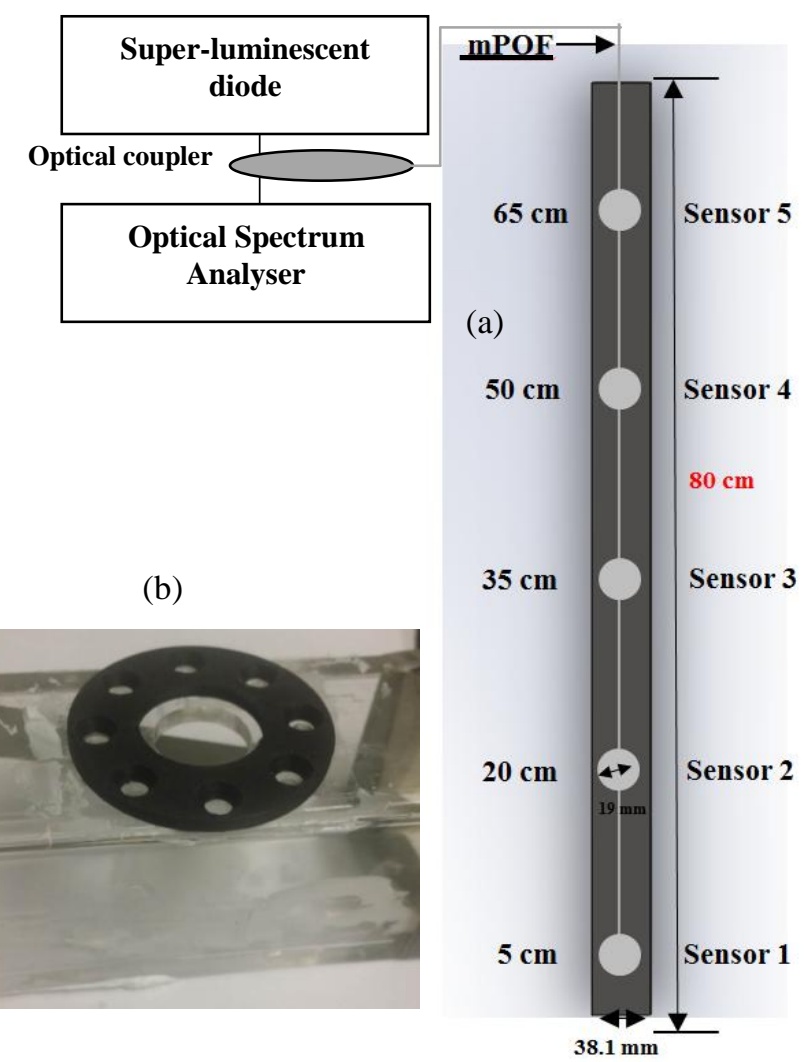

Fig.3. (a) Experimental apparatus and diagram of the acrylic tube sensor arrangement using mPOFBG array sensors. (b) Fixation of sensors to the square acrylic tube with retaining rings.

\section{RESULTS AND DISCUSSION}

The system was first characterized using water. The sensor performance was tested within a liquid level range of 0 to 75 $\mathrm{cm}$ and with a liquid level increment step of $2.5 \mathrm{~cm}$. Two experiments using different diaphragm/mPOFBG sensors were carried out, and three cyclic tests were performed to investigate both increasing and decreasing levels of the liquid to check for any hysteresis in the behavior of the sensors. It should be noted that all experiments showed a very good agreement between them, proving good repeatability between sensor responses. The results of the three cycles of each sensor are summarized in Table 1. Figs. 4 (a) and (b) show the first cycle of the first experiment for sensor 1 and sensor 3, respectively. The wavelength shift was extracted and the sensitivity of each sensor was calculated, showing a sensitivity 
of $98.6 \pm 0.3 \mathrm{pm} / \mathrm{cm}$ (sensor 1$), 98.1 \pm 0.2 \mathrm{pm} / \mathrm{cm}$ (sensor 2 ), $98.4 \pm 0.6 \mathrm{pm} / \mathrm{cm}$ (sensor 3), $97.6 \pm 0.8 \mathrm{pm} / \mathrm{cm}$ (sensor 4$)$, and $86.1 \pm 2.6 \mathrm{pm} / \mathrm{cm}$ (sensor 5). The insets in Figs. 4 (a) and (b) depict the residuals of each cycle (sensor 1 and sensor 3), showing a departure from linearity usually less than $0.1 \mathrm{~nm}$, predominantly arising as a result of a small amount of nonlinearity in the response. In terms of sensitivity variation between each sensor, one can see that there is a significant discrepancy coming from sensor 5. This was the only sensor where the fiber was not annealed following inscription and previous work had suggested that annealing led to a slight increase in the strain sensitivity of a POFBG recorded in a step index fiber [17]. Consequently, we carried out an investigation of the effects of annealing on the mPOF used for our sensors. In addition to studying the strain sensitivity, we investigated for the first time the annealing dependence of the force and stress sensitivity of the grating. The force sensitivity is important in this application because, due to its elastic modulus being higher than the diaphragm material, the POF will tend to restrict the pressure-induced expansion of the diaphragm. It is probably better then to think of the POFBG as being subjected to a pressure dependent force rather than having a pressure dependent strain imposed on it.

TABLE I

THREE CYCLES RESULTS OF ALL SENSORS: SENSITIVITY ANALYSIS.

\begin{tabular}{ccc}
\hline \hline & Increasing $(\mathbf{p m} / \mathbf{c m})$ & Decreasing $(\mathbf{p m} / \mathbf{c m})$ \\
\hline Sensor 1 & & \\
Cycle 1 & $98.4 \pm 0.3$ & $99.1 \pm 0.4$ \\
Cycle 2 & $98.7 \pm 0.2$ & $98.9 \pm 0.5$ \\
Cycle 3 & $98.5 \pm 0.4$ & $98.6 \pm 0.2$ \\
Sensor 2 & & \\
Cycle 1 & $98.1 \pm 0.2$ & $98.3 \pm 0.4$ \\
Cycle 2 & $98.4 \pm 0.2$ & $98.5 \pm 0.3$ \\
Cycle 3 & $98.7 \pm 0.4$ & $98.2 \pm 0.6$ \\
Sensor 3 & & \\
Cycle 1 & $98.2 \pm 0.6$ & $98.7 \pm 0.5$ \\
Cycle 2 & $98.7 \pm 0.3$ & $99.2 \pm 0.6$ \\
Cycle 3 & $98.9 \pm 0.4$ & $98.8 \pm 0.3$ \\
Sensor 4 & & \\
Cycle 1 & $97.4 \pm 0.8$ & $97.8 \pm 0.7$ \\
Cycle 2 & $98.2 \pm 0.9$ & $97.9 \pm 1.0$ \\
Cycle 3 & $97.9 \pm 0.6$ & $98.6 \pm 0.8$ \\
Sensor 5 & & \\
Cycle 1 & $86.1 \pm 2.5$ & $86.2 \pm 2.7$ \\
Cycle 2 & $86.4 \pm 2.3$ & $86.0 \pm 2.2$ \\
Cycle 3 & $86.5 \pm 2.1$ & $86.1 \pm 2.4$ \\
\hline \hline
\end{tabular}
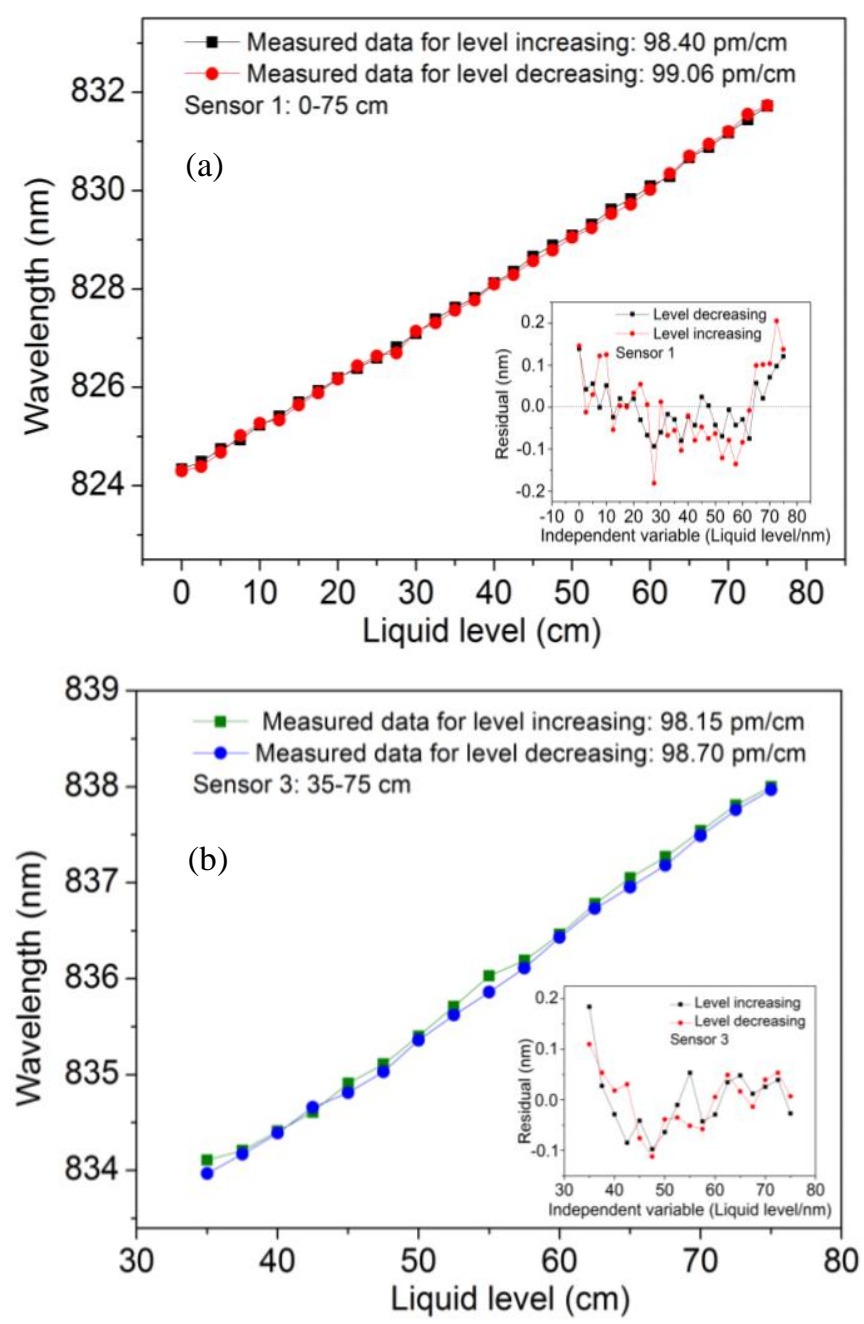

Fig. 4. Cyclic response using water for: (a) sensor 1 and (b) sensor 3. Insets: Residual plots for sensor 1 and sensor 3, respectively.

A grating with a nominal Bragg wavelength of $831.2 \mathrm{~nm}$ was fabricated in the doped mPOF used in the construction of the pressure sensors. The grating was attached using magnetic clamps between a fixed support and a translation stage enabling a controlled strain to be applied over a gauge length of $19.75 \mathrm{~cm}$. The fiber was stretched in steps of 100 microns up to a total strain of $0.5 \%$ over a period of approximately 7 min, while the Bragg wavelength was monitored using the broad band source and OSA used previously. The experiment was repeated three times to ensure the results were repeatable. Following the strain experiments, the sensitivity of the grating to force was assessed by hanging the fiber vertically from a support and attaching a mass of $2.990 \pm 0.005 \mathrm{~g}$. The wavelength change resulting from the application of the weight was determined (again, this was repeated 3 times to ensure reliable data). Finally the fiber diameter was measured using a microscope to enable the applied stress to be calculated.

Having completed this set of experiments, the fiber was annealed by placing the grating in water at $64^{\circ} \mathrm{C}$ for 2 minutes. This resulted in a permanent reduction of the Bragg 
wavelength of $1.3 \mathrm{~nm}$. Following this annealing process, the fiber was again characterized for strain, force and stress sensitivity as previously described. The results are summarized in Table 2, and are typical of those obtained for several other POFBGs fabricated in this fiber.

The amount of annealing carried out here is quite small compared the wavelength shifts induced in the POFBGs used for the pressure sensors. Nevertheless it may be seen from Table 1 that the annealing has a significant effect on the POFBG behavior, increasing the strain, force and stress sensitivity. We believe this process is responsible for the discrepancy observed in the pressure characteristics of sensor 5 in the level sensing experiment. To emphasize that, a very recent paper [18] shows that PMMA mPOFBGs annealed at high humidity have a superior response with a very low strain hysteresis, an improved strain sensitivity, and an increased stable operation temperature range.

TABLE II

EFFECTS OF ANNEALING ON POFBG SENSITIVITY TO STRAIN AND STRESS

\begin{tabular}{ccc}
\hline \hline & Before annealing & After annealing \\
\hline $\begin{array}{c}\text { Strain sensitivity } \\
(\mathrm{pm} / \mu \varepsilon)\end{array}$ & $0.68 \pm 0.01$ & $0.73 \pm 0.02$ \\
$\begin{array}{c}\text { Force sensitivity } \\
(\mathrm{pm} / \mu \mathrm{N})\end{array}$ & $0.109 \pm 0.001$ & $0.137 \pm 0.001$ \\
$\begin{array}{c}\text { Fiber diameter } \\
(\mu \mathrm{m})\end{array}$ & $128 \pm 2$ & $142 \pm 2$ \\
$\begin{array}{c}\text { Stress sensitivity } \\
(\mathrm{pm} / \mathrm{kPa})\end{array}$ & $0.14 \pm 0.02$ & $0.22 \pm 0.02$ \\
\hline \hline
\end{tabular}

Similar pressure array sensors were then fabricated to undertake the first tests using JET A-1 aviation fuel. This fuel presents a density around $0.810 \mathrm{~kg} / \mathrm{L}$ at $15{ }^{\circ} \mathrm{C}$ (less than water density, which is around $0.999 \mathrm{~kg} / \mathrm{L}$ at $15^{\circ} \mathrm{C}$ [19]). Two sensors were used, labeled sensors 1 and 3, as shown in Fig. 5 (a). The fuel depth was varied between $35 \mathrm{~cm}$ and $75 \mathrm{~cm}$ in steps of $5 \mathrm{~cm}$, giving a $40 \mathrm{~cm}$ measurement region as shown in Fig. 5 (a). Two cyclic tests were performed to investigate both increasing and decreasing levels of the liquid. Figs. 5 (b) and (c) show the first cycle of sensors 1 and 3, respectively. The wavelength shift was extracted and the sensitivity of each sensor was calculated, showing a sensitivity of $96.7 \pm 0.3$ $\mathrm{pm} / \mathrm{cm}$ (sensor 1) and $97.8 \pm 0.6 \mathrm{pm} / \mathrm{cm}$ (sensor 3). These are quite similar sensitivities to those obtained with water, whereas we might expect the results with fuel to be about $20 \%$ lower due to the reduced density. The explanation for this apparent discrepancy probably relates to the use of a different sealant for fixing the diaphragm to the fuel container.

The determination of liquid level was also made by linear regression to the wavelength shift from the sub-surface sensors at different depths. The liquid surface level is set at $48.0 \pm 0.1 \mathrm{~cm}$. The result is depicted in Fig. 5 (c), showing the equation of the linear fit. From the equation presented in Fig. 5 (c), an intercept value of $46.69 \pm 1.06 \mathrm{~cm}$ was computed. This proves for the first time that our sensing system is not affected by changes in the density of the liquid being monitored.
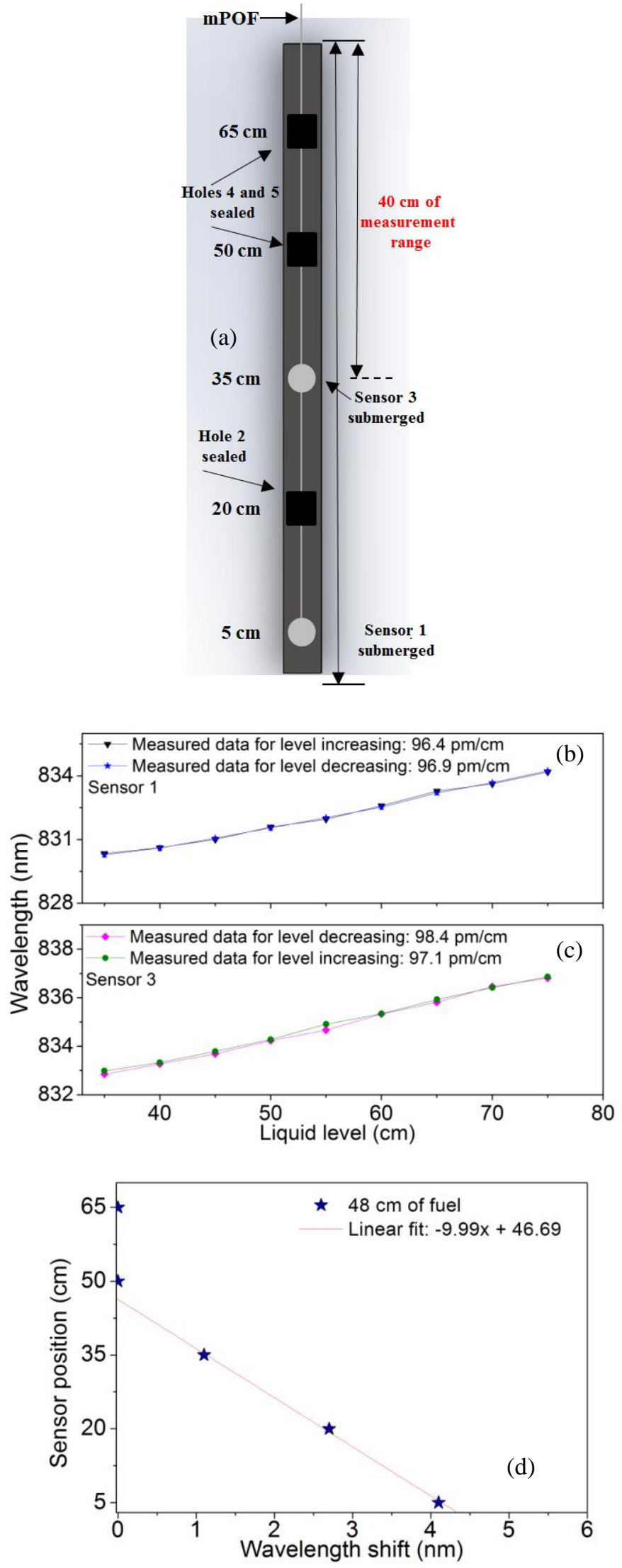

Fig. 5. (a) Diagram of the acrylic tube sensor arrangement showing the sensors submerged and the measurement range using fuel. Cyclic response using fuel for: (b) sensor 1 and (c) sensor 3. (c) Determination of liquid level using linear regression for a position of the fuel surface at $48 \mathrm{~cm}$. 
Despite these initially promising results with Jet A-1, the SILASTIC diaphragms were found to be unsuitable for longterm measurements. After a few hours exposed to fuel, the diaphragms were observed to swell to almost twice their original size, see Fig. 6 (a). Consequently a search was made for a more suitable material and a polyurethane resin from Liquid Lens [20] was chosen. This material is based on a mixing of two liquids - MF633 resin and DK780 catalyst - in a ratio of 100:100 by volume and curing at room temperature in 8 hours $\left(23^{\circ} \mathrm{C}, 40 \% \mathrm{RH}\right)$. This material shows less flexibility than the previous one, however it is resistant to the fuel. A diaphragm with the same dimensions as the previous manufactured diaphragms was placed in JET A-1 for more than 3 months with no measurable change in dimensions (see Fig. 6 (b)).

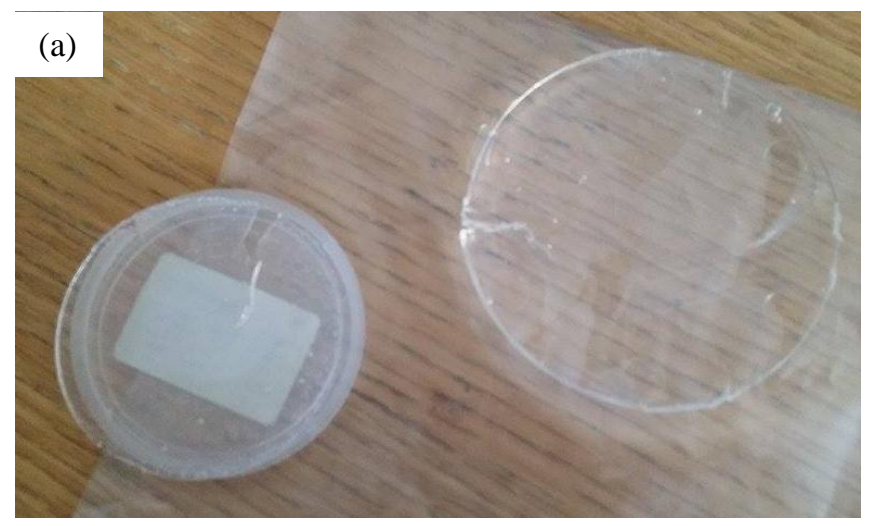

(b)

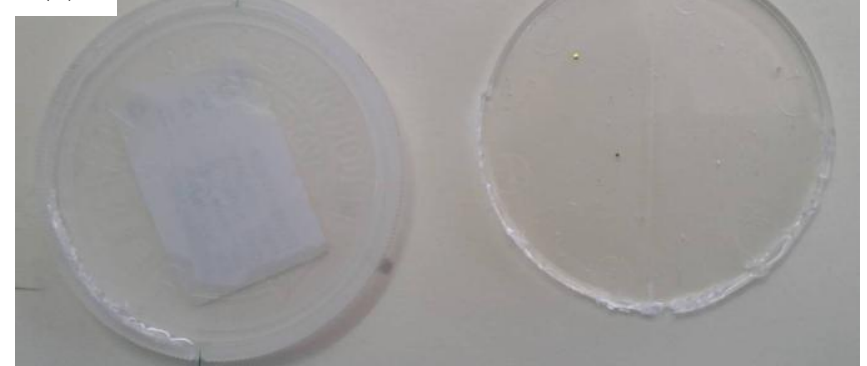

Fig. 6. (a) Diaphragms fabricated from SILASTIC. Left: as fabricated. Right: after exposure to fuel for several hours. (b) Diaphragms produced from polyurethane resin: left: as fabricated. Right: after exposure to fuel for more than 3 months with no measurable change in dimensions.

Sensors embedded in polyurethane were produced using the same procedure as earlier. The fuel level monitoring capability was tested within a liquid level range of 0 to $75 \mathrm{~cm}$ and with a liquid level increment step of $5 \mathrm{~cm}$. We conducted 2 series of experiments using different sensors. For each experiment, three cyclic tests were performed to investigate both increasing and decreasing levels of the liquid to check for any hysteresis in the behavior of the sensors. All cyclic tests showed a very good agreement and Figs. 7 (a-c) show the first cycle of the first experiment for sensor 1 , sensor 2 and sensor 3 , with the position of each sensor indicated in Fig. 3. The results of the three cycles of each sensor are summarized in Table 3. The wavelength shift was extracted and the sensitivity of each sensor was calculated, showing an average sensitivity of $38.5 \pm 0.5 \mathrm{pm} / \mathrm{cm}$. The achieved sensitivity is
TABLE III

THREE CYCLES RESULTS OF ALL SENSORS: SENSITIVITY ANALYSIS.

\begin{tabular}{ccc}
\hline \hline & Increasing $(\mathbf{p m} / \mathbf{c m})$ & Decreasing $(\mathbf{p m} / \mathbf{c m})$ \\
\hline Sensor 1 & & \\
Cycle 1 & $38.4 \pm 0.5$ & $38.7 \pm 0.4$ \\
Cycle 2 & $38.7 \pm 0.2$ & $38.5 \pm 0.3$ \\
Cycle 3 & $38.5 \pm 0.4$ & $38.6 \pm 0.2$ \\
& & \\
Sensor 2 & & $38.7 \pm 0.6$ \\
Cycle 1 & $38.4 \pm 0.4$ & $37.4 \pm 0.3$ \\
Cycle 2 & $38.2 \pm 0.4$ & $38.6 \pm 0.4$ \\
Cycle 3 & $37.5 \pm 0.2$ & \\
Sensor 3 & & $39.5 \pm 0.4$ \\
Cycle 1 & $38.8 \pm 0.2$ & $38.6 \pm 0.4$ \\
Cycle 2 & $38.4 \pm 0.5$ & $38.3 \pm 0.4$ \\
Cycle 3 & $38.5 \pm 0.3$ & \\
\hline \hline
\end{tabular}

less than with the SILASTIC silicone rubber due to the increased stiffness of the new material.

Once again, the determination of liquid level was made by linear regression to the wavelength shift from the sub-surface sensors at different depths. The liquid surface level is set at $48.0 \pm 0.1 \mathrm{~cm}$. Fig. 7 (d) shows the equation of the linear fit. From the equation presented, an intercept value of $47.5 \pm 1.0$ cm was computed.
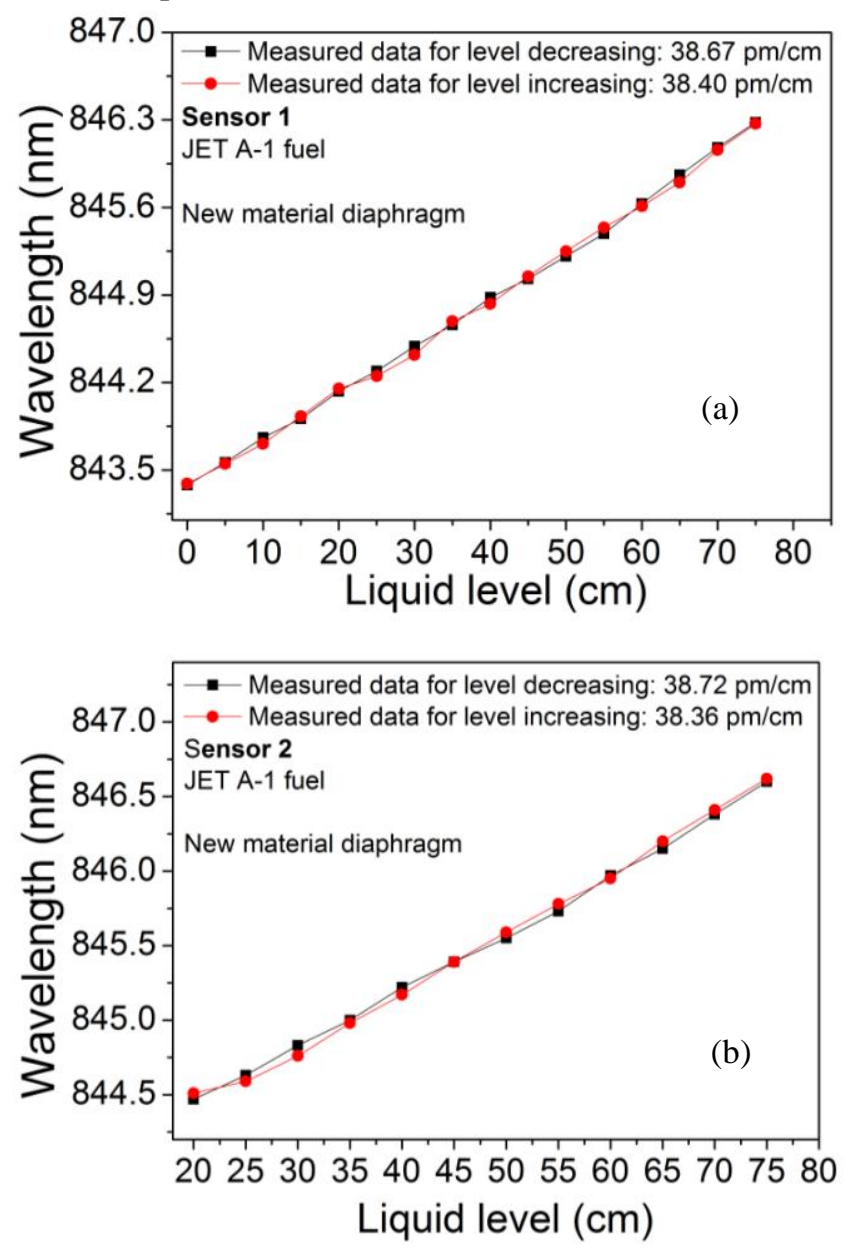

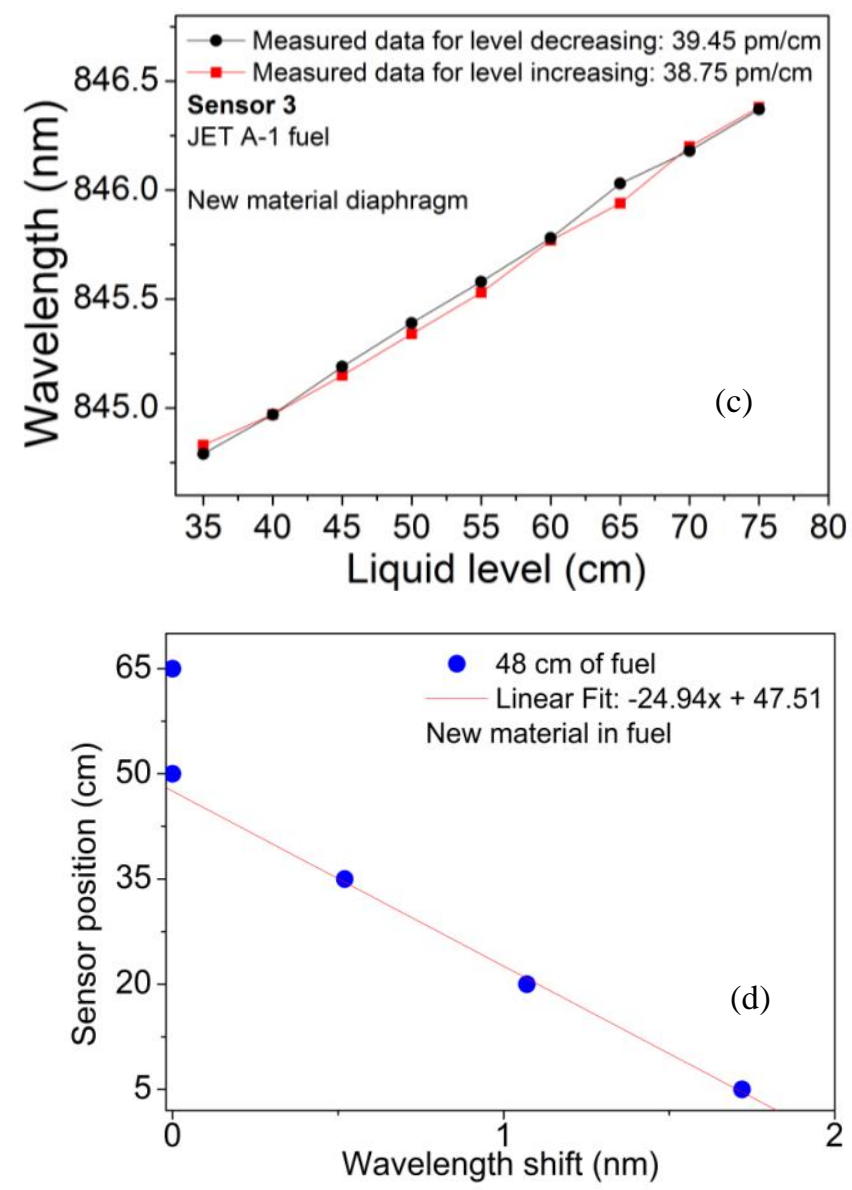

Fig. 7. Cyclic response using new diaphragm material (polyurethane resin from Liquid Lens [19]) in contact with JET A-1 for: (a) sensor 1, (b) sensor 2 and (c) sensor 3. (d) Determination of fuel level using linear regression for a position of the fuel surface at $48 \mathrm{~cm}$.

\section{CONCLUSION}

For the first time a high performance liquid level sensor based on a single fiber, multiplexed array of mPOFBG sensors embedded in silicone rubber diaphragms was fabricated and its performance studied in detail. The experimental results show that the proposed system had a high sensitivity to liquid level, and exhibited a highly linear and repeatable response. This mPOFBG array sensor, when compared with the best approach based on silica optical fiber published in the literature, exhibits a factor of 4 improvement in sensitivity ( 98 $\mathrm{pm} / \mathrm{cm}$ ). The level sensor has been used with JET A-1 aviation fuel and whilst initial performance was good, the tests revealed the diaphragm material to be unsuitable for prolonged use. An alternative polyurethane material has been successfully employed which shows good promise for long term use in fuel, albeit at the expense of a reduced sensitivity, due to the larger elastic modulus of the material.

Finally, initial investigations into the role of annealing on the sensing behavior of POFBGs has been undertaken, revealing that the strain, force and stress sensitivity of the devices are increased by just a modest amount of annealing.

\section{REFERENCES}

[1] R. Langton, C. Clark, M. Hewitt, L. Richards, "Aircraft Fuel Systems", Chichester, John Wiley \& Sons, United Kingdom, (2009).

[2] J. D. Weiss, "Fluorescent optical liquid-level sensor," Opt. Eng. 39, 2198 (2000).

[3] G. Betta, L. Ippolito, A. Pietrosanto, A. Scaglione, "Optical fiber-based technique for continuous-level sensing," IEEE Transactions on Instrumentation and Measurement 44, 686 (1995).

[4] H. K. Singh, S. K. Chakroborty, H. Talukdar, N. M. Singh, T. Bezboruah, "A New Non-Intrusive optical technique to measure transparent liquid level and volume,” IEEE Sens. J. 11, 391 (2011).

[5] C. Zhao, L. Ye, X. Yu, J. Ge, "Continuous Fuel Level Sensor Based on Spiral Side-Emitting Optical Fiber," Journal of Control Science and Engineering 2012, 267519 (2012).

[6] B. Yun, N. Chen, Y. Cui, "Highly sensitive liquid-level sensor based on etched fiber Bragg grating," IEEE Photon. Technol. Lett. 19, 1747 (2007).

[7] T. Guo, Q. D. Zhao, Q. Y. Dou, H. Zhang, L. F. Xue, G. L. Huang, X. Y. Dong, "Temperature-insensitive fiber Bragg grating liquid-level sensor based on bending cantilever beam," IEEE Photon. Technol. Lett. 17,2400 (2005).

[8] H. Y. Fu, X. W. Shu, A. P. Zhang, W. S. Liu, L. Zhang, S. L. He, I. Bennion, "Implementation and characterization of liquid-level sensor based on a long-period fiber grating Mach-Zehnder interferometer," IEEE Sens. J. 11, 2878 (2011).

[9] C. B. Mou, K. M. Zhou, Z. J. Yan, H. Y. Fu, L. Zhang, "Liquid level sensor based on an excessively tilted fiber grating," Opt. Commun. 305, 271 (2013).

[10] B. Gu, W. Qi, Y. Zhou, Z. Wu, P. P. Shum, F. Luan, "Reflective liquid level sensor based on modes conversion in thin-core fiber incorporating tilted fiber Bragg grating," Opt. Express 22, 11834 (2014).

[11] D. Sengupta, P. Kishore, "Continuous liquid level monitoring sensor system using fiber Bragg grating," Opt. Eng. 53, 017102 (2014).

[12] C. A. F. Marques, G.-D. Peng, D. J. Webb, "Highly sensitive liquid level monitoring system utilizing polymer fiber Bragg gratings," Opt. Express 23, 6058 (2015).

[13] C. A. F. Marques, G.-D. Peng, D. J. Webb, "High performance liquid level monitoring system based on polymer fiber Bragg gratings embedded in silicone rubber diaphragms", Proc. SPIE 9507, Microstructured and Specialty Optical Fibres IV, 95070N (2015).

[14] D. Sáez-Rodríguez, K. Nielsen, H. K. Rasmussen, O. Bang, D. J. Webb, "Highly photosensitive polymethyl methacrylate microstructured polymer optical fiber with doped core," Opt. Lett. 38, 3769 (2013).

[15] I. P. Johnson, D. J. Webb, K. Kalli, W. Yuan, A. Stefani, K. Nielsen, H. K. Rasmussen, O. Bang, "Polymer PCF Bragg grating sensors based on poly(methyl methacrylate) and TOPAS cyclic olefin copolymer," Proc. SPIE 8073, 80732V (2011).

[16] http://www.dowcorning.com/content/rubber/

[17] W. Yuan, A. Stefani, M. Bache, T. Jacobsen, B. Rose, N. HerholdtRasmussen, F.K. Nielsen, S. Andresen, O.B. Sørensen, K.S. Hansen, O. Bang, "Improved thermal and strain performance of annealed polymer optical fiber Bragg gratings," Opt. Commun. 284, 176 (2011).

[18] G. Woyessa, K. Nielsen, A. Stefani, C. Markos, O. Bang, "Temperature insensitive hysteresis free highly sensitive polymer optical fiber Bragg grating humidity sensor," Opt. Express 24, 1206 (2016).

[19] http://www.pg.gda.pl/chem/Dydaktyka/Analityczna/MISC/Water_densit y_Pipet_Calibration_Data.pdf

[20] http://www.liquid-lens.com/advanced2 resin.html

C. A. F. Marques received the M.S. degree and the Ph.D. degree in Physics Engineering from the University of Aveiro, Portugal, in 2008 and 2013, respectively. From 2007 to March 2014, he was a Research Fellow in the Instituto de Telecomunicações, Aveiro, Portugal. Then, he was a Marie Curie Fellow in the Aston Institute of Photonic Technologies, Aston University, Birmingham, U.K until March 2016. Currently, he is a research Fellow in the Instituto de Telecomunicações and Physics Department \& I3N, University of Aveiro, Portugal. His main interests include optical fiber devices and fabrication of short/long period gratings for optical communications and sensing applications. He authored or co-authored more than 75 journal and 
conference technical papers with emphasis on optical communications and sensing applications.

A. Pospori received the B.A degree in Electrical \& Electronic Engineering from Cyprus University of Technology (CUT), Cyprus, in 2013. He is currently a Marie Curie Early Stage Researcher - PhD student, in the Aston Institute of Photonic Technologies, Aston University, Birmingham, U.K. His knowledge includes inscription and micro-machining using femtosecond laser systems. His current research includes polymer fiber grating UV fabrication and testing.

D. Sáez-Rodríguez received the B.A degree in physics from the University of Valencia, Valencia, Spain, in 2005, and the Ph.D. degree in physics from the University of Valencia, Valencia, Spain, in 2012. He was a Marie Curie Fellow at Aston University for two years. He is currently a Research Fellow in the Juan de lacierva Program, Universidad Politecnica de Valencia, Valencia, Spain. His main interests include both polymer and silica optical fiber and fabrication of long and short period gratings for applications in communications and sensing.

K. Nielsen received the M.S. degree in physics and the Ph.D. degree from the Technical University of Denmark, Lyngby, Denmark, in 2008 and 2011, respectively. He is currently a Development Engineer at the Department of Photonics Engineering, Technical University of Denmark. His main interests include microstructured polymer optical fibers and their applications in sensing.

O. Bang received the M.S. degree in electrical engineering and the Doctor of Philosophy degree in nonlinear physics from the Technical University of Denmark (DTU), Lyngby, Denmark, in 1991 and 1993, respectively. He was a Postdoctoral Fellow with Laboratoire de Physique, École Normale Supérieure de Lyon, France, from 1993 to 1995, where he worked on discrete physical models of the nonlinear dynamics of biomolecules. From 1995 to 1999, he was a Research Fellow with the Optical Sciences Centre, Australian National University, where he worked theoretically on nonlinear optics, in particular on solitons and modulational instability in materials with a quadratic nonlinearity and quasi-phase-matching gratings. In 1999, he became an Associate Professor at the Department of Informatics and Mathematical Modeling at DTU, continuing the work on nonlinear optics in quadratic nonlinear crystals. In 2003, he moved to the Department of Photonics Engineering, DTU Fotonik, where he became a Professor in advanced photonics materials in 2011. He is the Head of Fiber Sensors \& Supercontinuum Group working on fabricating polymer optical fibers and polymer photonic crystal fibers (PCFs) and using them for sensing of biomolecules, strain, humidity, and temperature, in particular with Fiber Bragg gratings. Another main part of his work is on supercontinuum generation and nonlinear fiber-optics in silica and softglass PCFs, as well as its use in imaging and spectroscopy. He is a Member of the Optical Society of America and the Danish Optical Society.

D. J. Webb received B.A. degree in physics from the University of Oxford, Oxford, U.K., in 1983 and the Ph.D. degree in physics from University of Kent, Canterbury, U.K., in 1989. He is a Professor of photonics and Deputy Director of the Aston Institute of Photonic Technologies, Aston University, Birmingham, U.K. He previously spent ten years at the University of Kent and has also worked at Oxford University and for GEC Research. His main interests include optical fiber sensing using in-fiber Bragg gratings and fiber interferometers. His current research includes medical and biochemical applications of optical sensing technology and the development of polymer optical fiber based grating devices. He has published around 400 journal and conference papers on these subjects. 